\title{
Idiopatik erkek infertilitesinde antioksidan kompleks tedavinin etkinliğinin değerlendirilmesi
}

\author{
Evaluation of the effectiveness of antioxidant complex treatment in \\ idiopatic male infertility \\ Ünal Öztekin®, Fatih Fırat²®
}

\section{öz}

AMAÇ: İnfertil erkeklerin semen analizlerinde görülen oligoastenoteratozoospermi durumunun \%30'undan fazlasında etiyolojik bir neden bulunamaz ve idiopatik infertilite olarak tanımlanır. Bu çalışmanın amac1, etiyolojik bir neden tespit edilemeyen ve idiopatik erkek infertilitesi olarak kabul edilen hastalarda antioksidan kompleks kullanımının, semen parametreleri üzerindeki etkisini değerlendirmektir.

GEREÇ VE YÖNTEM: Çalışmaya, Ocak 2018 - Ocak 2020 arasında idiopatik erkek infertilitesi tanısı konulan, primer veya nüks varikoseli, hormonal patolojisi olmayan ve testis hacimleri normal olarak değerlendirilen 92 hasta alınmıştır. Tüm hastalar, içeriğinde L-arjinin, L-karnitin, Magnezyum, Ginseng ekstresi, çinko, Koenzim Q10, Vitamin D, Selenyum olan ve gida takviye edici olarak adlandırılan preparatlardan, yaklaşık sekiz saatte bir olmak üzere günde üç kez düzenli olarak altı ay boyunca kullandı. Tedavi öncesinde ve sonrasındaki 6 . ayda semen parametreleri çalışılarak, değişimler analiz edildi.

BULGULAR: Hastaların yaş aralığı 20-40 (ortalama: 28,9) idi. Antioksidan tedavi öncesi ve sonrası semen parametreleri karşılaştırıldığında semen hacminde anlamlı bir değişim gözlenmedi. Sperm sayısı, progresif ve total motilite incelendiğinde altı aylık tedavi sonrası anlamlı düzelme mevcuttu $(\mathrm{p}<0,05)$

SONUCุ: Oksidatif stres erkek faktörlü infertilitenin önemli nedenlerinden biridir ve tedavisinde antioksidan kompleks ajanlar kullanılmaktadır. Çalışmamızın sonuçları antioksidan tedavinin sperm patolojilerini iyileştirmeye katkı sağlayabileceğini düşündürmektedir. Bu açıdan tedavi edilebilir etiyolojik faktör saptanamayan ve idiopatik infertilite olarak kabul edilen hastalarda antioksidan kompleks tedaviler önerilebilir.

Anahtar Kelimeler: Erkek infertilitesi, antioksidan tedavi, semen parametreleri, sperm

\section{ABSTRACT}

OBJECTIVE: In male infertility in more than $30 \%$ of oligoasthenoteratozoospermia patients etiological cause cannot be found and it is defined as idiopathic infertility. The aim of this study is to evaluate the effect of antioxidant complex treatment on semen parameters in patients whose etiological cause can not be identified and considered as idiopathic male infertility.

MATERIAL AND METHODS: Ninety two patients patients with idiopathic male infertility diagnosed between January 2018 and January 2020, without primary or recurrent varicocele, without hormonal pathology and with normal testicular volumes were included in the study. All patients used three times a day regularly for 6 months, from supplements that contain L-arginine, L-carnitine, Magnesium, Ginseng extract, zinc, Coenzyme Q10, Vitamin D and Selenium. The semen parameters were evaluated before and 6 months after the treatment and the changes were analyzed.

RESULTS: The age range of the patients was 20-40 (mean: 28.9). Semen parameters were compared before and after antioxidant treatment and there was no significant change in semen volume. There was a significant improvement after 6 months of treatment in sperm count, progressive and total motility $(\mathrm{p}<0.05)$

CONCLUSION: Oxidative stress is one of the important causes of male factor infertility and antioxidant complex agents are used in the treatment. The results of our study suggest that antioxidant therapy can contribute to improving sperm pathologies. In this regard, antioxidant complex treatments can be recommended in patients who cannot be detected as a curable etiological factor and are considered as idiopathic infertility.

Keywords: Male infertility, Antioxidant therapy, Semen parameters, Sperm

[1] Evli çiftlerin \%15 den fazlası infertilite ile sonuçlanan çeşitli fertilite problemleri ile karşı karşıyadır ve bu çiftlerin yaklaşık \%50 sinde erkek nedenli faktörler gözlemlenmektedir. ${ }^{[2]}$ Erkek faktörü sıklıkla semen patolojileri ile karşımıza çıkmaktadır ve diyet, yaşam tarzı, çevresel faktörler, ilaçlar, toksik maddeler semen üzerinde olumsuz etkileri nedeni ile suçlanmıştır. ${ }^{[3]}$ İnfertil erkeklerin semen analizlerinde görülen oligoastenoteratozoospermi (OAT) durumunun \%30'undan fazlasında etiyolojik bir neden bulunamaz ve idiopatik infertilite olarak tanımlanır. ${ }^{[4]}$

Oksidan-antioksidan dengenin oksidatif stres yönüne kayması ile testis içerisinde üretilen reaktif oksijen 
türlerinin (ROS) spermatogenez üzerindeki negatif etkisiyle semen parametrelerinde bozukluklara neden olduğu ve bunun sonucunda idiopatik infertilite meydana geldiği bilinmektedir. ${ }^{[5]}$ İdiopatik infertilitede, oksidatif stres etiyolojisi yaygın olarak araştırılmış ve erkek faktörü olarak subfertilitenin \%25-87'sinde rol oynadığı bildirilmiştir. ${ }^{[6]}$ Etiyolojik faktörün net olarak tespit edilemediği bu hastalarda, kesin bir tedavi seçeneği olmaması nedeni ile çeşitli ampirik tedaviler uygulanmakta ve sıklıkla hormonal preperatlar ve antioksidanlar kullanılmaktadır. ${ }^{[4]}$ Antioksidan olarak en çok asetil-L-karnitin, L-karnitin fumarat, glutatyon, vitamin $\mathrm{E}$ ve $\mathrm{C}$, karnitin, arjinin, koenzim-Q10, $\mathrm{N}$-asetilsistein, selenyum, çinko, folik asit ve likopen içeren gıda takviyesi ilaçlar sıklıkla kullanılmaktadır. $^{[2,7]}$ Literatürde antioksidan kompleks tedavilerin ROS kaynaklı sperm hasarını azaltarak spermatogenezi iyileştirici etkinliği olduğu vurgulanmıştır. ${ }^{[6]} \mathrm{Bu}$ açıdan özellikle son yıllarda antioksidan kompleks preperatların kullanımı yaygınlaşmıştır. Ancak literatürde antioksidanların kullanım süresi etkinliği ve dozu konusunda net sınırlar bulunmamaktadır.

Bizde çalışmamızda erkek infertilitesi nedeniyle başvuran ve idiopatik erkek infertilitesi tanısı alan hastalarda, klinik pratikte kullandığımız antioksidan kompleks tedavinin yaygın olarak bilinen risk faktörlerini (sigara, varikosel vs.) dışlayarak daha izole bir grupta altı aylık tedavi sonuçlarımızı değerlendirmeyi hedefledik.

\section{GEREÇ VE YÖNTEM}

Bu çalışmada, iki yıllık süreçte (Ocak 2018 - Ocak 2020) üroloji kliniğimize infertilite araştırılması nedeni ile başvuran 18 yaş üzeri hastaların verileri retrospektif olarak değerlendirildi. Kliniğimizin infertilite formlarından ve hastane kayıtları incelenerek, çalışma kriterlerini sağlayan 92 hastanın sonuçları analiz edildi. Onsekiz yaş altı, tek veya çift taraflı orşiektomi yapılmış, karyotip anomalisi, kemoterapi ve radyoterapi öyküsü olan, primer veya nüks varikoseli olan ve bir yıldan kısa sürede varikoselektomi hikayesi olan hastalar, hormonal patolojisi (hiper/ hipogonadizm, hiperprolaktinemi, hiper/hipotroidi) olan, testis hacmi $<14 \mathrm{~mL}$, vücut kitle indeksi (VKI) $\geq 30 \mathrm{~kg} /$ $\mathrm{m}^{2}$, kriptozoospermi $(\leq 1 \mathrm{milyon} / \mathrm{mL})$ olan, sigara ve alkol kullanan hastalar çalışma dışı bırakıldı. Hastaların poliklinik muayenesi sırasında boy ve kilo ölçümleri, fizik muayeneleri yapıldı. Hormonlar olarak Prolaktin (PRL), Follikül Stimülan Hormon (FSH), Luteinizan Hormon (LH), Estradiol (E2), Total Testosteron (TT) tetkikleri çalışıldı. Cinsel perhiz süresi 3-7 gün olmak üzere semen analizleri istendi. Testis ölçümleri prader orşidometre kullanılarak yapıldı. Semen analiz sonuçları Dünya Sağlık Örgütünün
2010 yılı beşinci baskısında yayınlanan kılavuz referans alınarak değerlendirildi. ${ }^{[8]}$

Çalışma kriterlerini sağlayan hastaların semen parametreleri olarak; semen hacmi, sperm sayısı, progresif ve total motilite oranları hesaplandı. Tüm hastalar, içeriğinde Larjinin, L-karnitin, Magnezyum, Ginseng ekstresi, çinko, Koenzim Q10, Vitamin D ve Selenyum olan gıda takviye edici olan preparatlardan yaklaşık sekiz saatte bir olmak üzere günde üç kez düzenli olarak altı ay boyunca kullandı. Tedavi öncesinde ve sonrasındaki 6 . ayda semen parametreleri çalışılarak, değişimler analiz edildi.

\section{İstatistiksel Analiz}

Tüm istatistiksel testler Statistics Package for Social Sciences version 25 (IBM SPSS, Chicago, IL) programı kullanılarak yapıldı. Hastalara ait tanımlayıcı veri analizi yapılarak, non-parametrik verilerin tedavi öncesi ve sonrası karşılaştırılmasında Wilcoxon Signed Ranks Test kullanıld. $\mathrm{p}<0,05$ istatistiksel olarak anlamlı kabul edildi.

\section{BULGULAR}

Çalışmaya, yaş aralığı 20-40 (ortalama: 28,9) olan toplam 92 hasta dahil edildi. Hastaların ortalama VKİ 25,0 kg/ $\mathrm{m}^{2}$ idi. Sağ testis hacmi ortalama $17,17 \mathrm{~mL}$ iken sol testis hacmi ortalama 17,26 mL idi. Hastalara ait demografik, fizik muayene ve hormon sonuçlarının ortalama ve minimum-maksimum değerleri Tablo 1'de verilmiştir.

Tablo 1. Antioksidan tedavi alan hastaların demografik, fizik muayene ve hormonal veri dağılımları

\begin{tabular}{|c|c|}
\hline Hasta Sayısı (n) & 92 \\
\hline Yaş (mean $\pm S D)(\min -\max )$ & $28,99 \pm 4,5(20-40)$ \\
\hline $\begin{array}{l}\text { VKi }\left(\mathrm{kg} / \mathrm{m}^{2}\right)(\text { mean } \pm \mathrm{SD}) \\
(\min -\max )\end{array}$ & $25,00 \pm 3,0(19,16-29,76)$ \\
\hline $\begin{array}{l}\text { Sağ testis hacim (mL) } \\
\text { (mean } \pm \text { SD) (min-max) }\end{array}$ & $17,17 \pm 1,6(14-20)$ \\
\hline $\begin{array}{l}\text { Sol testis hacim (mL) } \\
\text { (mean } \pm \text { SD) (min-max) }\end{array}$ & $17,26 \pm 1,5(14-20)$ \\
\hline $\begin{array}{l}\mathrm{PRL}, \mathrm{ng} / \mathrm{mL}(\text { mean } \pm \mathrm{SD}) \\
\text { (min-max) }\end{array}$ & $9,07 \pm 2,9(3,5-16,1)$ \\
\hline $\begin{array}{l}\mathrm{FSH}, \mathrm{mIU} / \mathrm{mL}(\text { mean } \pm \mathrm{SD}) \\
(\min -\max )\end{array}$ & $3,29 \pm 1,1(1,5-5,5)$ \\
\hline $\begin{array}{l}\mathrm{LH}, \mathrm{mIU} / \mathrm{mL}(\text { mean } \pm \mathrm{SD}) \\
(\min -\mathrm{max})\end{array}$ & $3,47 \pm 1,3(1,6-7,4)$ \\
\hline $\begin{array}{l}\mathrm{E} 2, \mathrm{ng} / \mathrm{L}(\operatorname{mean} \pm \mathrm{SD}) \\
(\min -\max )\end{array}$ & $19,64 \pm 6,0(8-38)$ \\
\hline $\begin{array}{l}\mathrm{TT}, \mathrm{ng} / \mathrm{dL}(\text { mean } \pm \mathrm{SD}) \\
(\min -\mathrm{max})\end{array}$ & $472,70 \pm 186,3(250,6-910,2)$ \\
\hline
\end{tabular}


Antioksidan tedavi öncesi ve sonrası semen parametreleri karşılaştırıldığında semen hacminde anlamlı bir değişim gözlenmedi. Sperm sayısı, progresif ve total motilite incelendiğinde altı aylık tedavi sonrası istatistiksel olarak anlamlı bir atış mevcuttu $(\mathrm{p}<0,05)$ (Tablo 2).

Tablo 2. Antioksidan tedavilerin 6 . ay sonundaki sperm parametreleri üzerine etkisi

\begin{tabular}{lccc} 
& $\begin{array}{c}\text { Tedavi } \\
\text { Öncesi }\end{array}$ & $\begin{array}{c}\text { Tedavi } \\
\text { sonrası }\end{array}$ & P değeri \\
\hline Hacim, ml (mean \pm SD) & $3,03 \pm 1,38$ & $2,96 \pm 1,24$ & 0,944 \\
$\begin{array}{l}\text { Sperm sayı, mil/mL } \\
\text { (mean } \pm \text { SD) }\end{array}$ & $27,65 \pm 19,40$ & $34,37 \pm 25,09$ & $<0,001$ \\
$\begin{array}{l}\text { Progresif motilite, (type } \\
\text { A) (\%) }\end{array}$ & $17,28 \pm 12,53$ & $23,27 \pm 15,67$ & $<0,001$ \\
$\begin{array}{l}\text { Total motilite, } \\
\text { (type A+B) (\%) }\end{array}$ & $38,55 \pm 19,03$ & $44,36 \pm 14,57$ & 0,001 \\
\hline
\end{tabular}

SD, standard deviasyon.

\section{TARTIȘMA}

Erkek infertilitesine neden olabilecek anatomik, fonksiyonel, hormonal ve genetik hastalıklar tanımlanmasına rağmen vakaların çoğunda anormal spermatogenez ve sperm fonksiyon bozuklukları karşımıza çıkar. İdiopatik infetilite olarak tanımlanan bu durumun etiyolojisinde oksidatif stres en sık bildirilen etiyolojik faktördür. ${ }^{[9]}$ Reaktif Oksijen Türleri üretiminin sonucu ile ortaya çıkan oksidatif stres hücre ve dokularda yıkıcı etkilere neden olmaktadir. Spermatozoa membranı, lipid peroksidasyonu sonucu oksitlenebilen yüksek miktarda doymamış yağ asitleri içerir. Ayrıca sitoplazmasında çok az miktarda ROS’u nötralize edebilecek enzimler bulunur. Bu nedenle spermatozoa ROS'un zararlı etkilerine duyarlıdır. Hücre membranındaki lipitlerin oksidatif stres ile indüklenmesi sonucu, membran bütünlügünün kaybı ile geçirgenliğin artması, hücresel enzimlerin inaktivasyonu, yapısal DNA hasarı ve hücre apopitozuna yol açabilir. Bu durum, sayısı ve aktivitesi ile motilitesi azalmış ve morfolojisi bozulmuş spermler olarak sonuçlanır. ${ }^{\text {9-11] }}$

Reaktif Oksijen Türleri'nin oksidatif stres ile spermler üzerindeki oluşturabilecekleri bu olumsuz etkileri azaltarak spermatogenezisi iyileştirmek için çeşitli antioksidan ajanlar ve takviye edici gıda preparatları sıklıkla kullanılmaktadır. İnfertil erkeklerin oral antoksidanlarla tedavi edilmesinin mantığı, seminal oksidatif stresin kısmen seminal antioksidanlardaki eksikliğine bağlı olduğu düşüncesine dayanmaktadır. Seminal oksidatif stresin antioksidanlar ile tedaviden önce ve sonra baskılanmasını irdeleyen çalışma sayısı azdır. Comhaire ve ark.'nın ${ }^{[12]} 27$ infertil hasta üzerinde antioksidan (N-asetil-sistein veya
A ve E vitaminleri) tedavi öncesi ve sonrası seminal ROS değerlerini, sperm membran fosfolipitlerinin esansiyel yağ asitlerini ve sperm oksitlenmiş DNA analizini yaptıkları çalışmalarında; tedavinin sperm motilitesi ve morfolojisini iyileştirmediği, oligozoospermik hastalarda sperm konsantrasyonunu artırdığını bildirmişlerdir. Ayrıca seminal ROS ve oksitlenmiş DNA oranında anlamlı derecede azalma tespit etmişlerdir. ${ }^{[12]}$ Sperm membranının fonksiyonel kapasitesinin iyileşmesi spermatozoanın fertilizasyon potansiyelini arttırabileceğini, yüksek düzeyde oksidatif hücre hasarı gösterilen OAT hastalarında antioksidanların iyileştirici yönde genel bir etkisinin olduğu bildirilmiştir. ${ }^{[12-14]}$ Çoklu antioksidan preparatların (antioksidan kompleks) kullanıldığı çalışmalarda literatürde mevcuttur. Arafa ve ark.'nın antioksidan komplex kullanılarak yaptığı çalışmalarında, idiopatik infertilitesi olan 148 hastayı üç ay takip ettiklerinde, tedavi sonrası sperm sayı ve motilitesinde artış ile seminal oksidasyonda ve sperm DNA fragmantasyonunda azalma tespit etmişlerdir. ${ }^{[15]}$ Bassiri ve ark.'nın, en az bir kez yardımc1 üreme tekniği kullanılan ve başarısızlıkla sonuçlanan erkek faktörlü infertil çiftlerde, dört ay boyunca düzenli olarak antioksidan komplex kullanımı önerdikleri hasta grubundan takibi tamamlayabilen 25 hastanın sperm sayısı ve hareketlerinde artış görememekle birlikte morfoloji, nükleer matürasyon, DNA fragmantasyonu ve lipit peroksidasyonunda anlamlı düzelme ile 10 hastada klinik gebelik elde etmişlerdir. ${ }^{[16]}$ Yine benzer şekilde domuzlar üzerinde yapılan bir çalışmada, tropikal bölgelerde yaz aylarında sıcaklığın yüksek olmasına bağlı ısı stresinin sperm DNA bozmasına karşın, antioksidan takviyenin bu olumsuz etkilere karşı koruyuculuğu bildirilmiştir. ${ }^{[17]}$

Literatürde farklı dozlarda ve sürelerde yapılan çalışmalarda genel olarak antioksidan tedavi rejimlerinden sonra semen parametrelerinde anlamlı iyileşmeler görülmüştür. Antioksidanların etkinliğinin değerlendirildiği 16 çalışmay1 inceleyen Cochrane meta-analizinde sperm konsantrasyonu açısından plesaboyla karşılaştırıldığında, yedi çalışmanın 3. ve 6. ay sonuçlarında artış saptanmadığı ancak altı çalışmada 6. ayda, üç çalışmada da 9. ayda artış görüldüğü bildirilmiştir. ${ }^{[18]}$ Ancak bu meta-analizde değerlendirilen çalışmalar antioksidan komplex tedaviden çok tek bir antioksidanın değerlendirildiği çalışmalardır. Antioksidanları etki mekanizmalarını inceleyen başka bir çalışmada, Vitamin C, Vitamin E ve karnitinlerin, ROS'ları nötralize ederek, Çinkonun nicotinamide adenine dinucleotide phosphate oksidaz inhibisyonu ile, selenyumun enzimatik antioksidan aktiviteyi güçlendirerek, Koenzim Q10'un ise mitokondriyal elektron taşıma sisteminde ara serbest radikalleri temizleyerek etki gösterdiği gösterilmiştir. ${ }^{[19]}$ Yine 
bu çalışmada mevcut kanıtlara dayanarak çeşitli klinik senaryolara göre antioksidanlar önerilmiştir. Oligozoospermi ve astenozoospermi durumunda; Vitamin E, vitamin C, karnitinler, Koenzim Q10, selenyum ve çinko, teratozoospermi durumunda; Vitamin E, selenyum ve çinko özellikle önerilen antioksidanlardır. ${ }^{[19]}$ Çoklu antioksidan ajanlardan oluşan komplex tedavi protokollerinin değerlendirildiği çalışmalarda, içeriğinde özellikle vitamin C, vitamin E ve Koenzim Q10 bulunan preparatların tedavide kullanımının idiopatik infertil erkeklerde semen parametrelerini anlamlı derecede düzelttiği bildirilmiştir. ${ }^{[20]}$ Günümüz klinik pratiğinde bu antioksidanların birlikte kompleks olarak kullanılabildiği takviye edici preparatlar sıklıkla kullanılmaktadır. Bu tedavilerin yanı sıra antioksidan gida tercihleri arttırılarak beslenmenin de oksidatif stresin azaltılmasında katkı sağlayabileceği ve yaşam tarzı değişikliğinin önerildiği çalışmalarda mevcuttur. ${ }^{[21]}$ Her ne kadar literatür verileri antioksidanların etkinliğini vurgulasa da, semen parametrelerinde düzelme olmadığını gösteren çalışmalarda mevcuttur. ${ }^{[22,23]}$

Biz çalışmamızda, içeriğine yukarıda değindiğimiz gıda takviye edici olarak kullanılan preparatı düzenli olarak altı ay kullanan hastaların sonuçlarını değerlendirdik. Tedavi sonrası semen hacminde değişiklik olmamasına karşın sperm konsantrasyonunda ve motil sperm oranlarında anlamlı artış tespit ettik. Sonuçlarımız literatür verilerine paralel olarak antioksidan tedavi rejimlerinin idiopatik infertilitede sıklıkla karşılaşılan semen patolojilerine olumlu etki etki edebileceği yönündedir.

Çalışmamızın retrospektif olarak dizayn edilmesi ve seminal oksidatif stres belirteçlerinin çalışılmamış olması limitasyonumuz olarak değerlendirilebilir. Ayrıca 6. ay hormonal değerlendirme sonuçlarımızın olmaması ve gebelik takip verilerinin bulunmaması diğer limitasyonlarımız olarak belirtilebilir.

\section{SONUÇ}

Erkek infertilitesinde antioksidan tedavinin seminal parametreler ve gebelik oranları üzerine olumlu etkileri olduğu kanıta dayalı veriler ile desteklenmeye çalışılmaktadır. Bizim çalışmamızın sonuçları da bu tedavi rejimlerinin sperm patolojilerini iyileştirmede katkı sağlayabileceğini düşündürmektedir. Bu açıdan tedavi edilebilir etiyolojik faktör saptanamayan idiopatik infertilite olarak kabul edilen hastalarda antioksidanlar önerilebilir. Ancak seminal oksidatif markırların ve gebelik oranlarının değerlendirildiği daha büyük örnekleme sahip, çok merkezli ve uzun süreli randomize prospektif çalışmalara ihtiyaç vardır.

\section{Hakem Değerlendirmesi}

Dış bağımsız

Çıkar Çatışması

Yazarlar çıkar ilişkisi olmadığını beyan etmişlerdir.

Finansal Destek

Herhangi bir mali destek alınmamıştır.

\section{Peer-review}

Externally peer-reviewed.

Conflict of Interest

No conflict of interest was declared by the authors.

Financial Disclosure

No financial disclosure was received.

\section{KAYNAKLAR}

1. Öztekin U, Caniklioğlu M, Sarı S, Selmi V, Gürel A, Işıkay L. Evaluation of Male Infertility Prevalence with Clinical Outcomes in Middle Anatolian Region. Cureus 2019;11:e5122. [CrossRef]

2. Dong L, Zhang X, Yang F, Li J, Yu X, Li Y. Effect of oral alphalipoic acid (ALA) on the treatment of male infertility: A protocol for systematic review and meta-analysis. Medicine (Baltimore) 2019;98:e18453. [CrossRef]

3. Gabrielsen JS, Tanrikut C. Chronic exposures and male fertility: the impacts of environment, diet, and drug use on spermatogenesis. Andrology 2016;4:648-61. [CrossRef]

4. Garg H, Kumar R. Empirical Drug Therapy for Idiopathic Male Infertility: What is the New Evidence? Urology 2015;86:1065-75. [CrossRef]

5. Saad AB, Rjeibi I, Brahmi N, Elaloui E, Zouari N. Nicotineinduced oxidative stress, testis injury, AChE inhibition and brain damage alleviated by Mentha spicata. Inflammopharmacology 2019. [CrossRef]

6. Smits RM, Mackenzie-Proctor R, Yazdani A, Stankiewicz MT, Jordan V, Showell MG. Antioxidants for male subfertility. Cochrane Database Syst Rev 2019;3:CD007411. [CrossRef]

7. Gamidov SI, Ovchinnikov RI, Popova AY. Double-blind, randomized placebo-controlled study of efficiency and safety of complex acetyl-L-carnitine, L-carnitine fumarate and alpha-lipoic acid (Spermactin Forte) for treatment of male infertility. Urologiia 2019:62-8. [CrossRef]

8. World Health Organization: Laboratory manual for the examination and processing of human semen, 5th ed. WHO Press, Geneva; 2010.

9. Walczak-Jedrzejowska R, Wolski JK, Slowikowska-Hilczer J. The role of oxidative stress and antioxidants in male fertility. Cent European J Urol 2013;66:60-7. [CrossRef]

10. Aprioku JS. Pharmacology of free radicals and the impact of reactive oxygen species on the testis. J Reprod Infertil 2013;14:158-72. https://www.ncbi.nlm.nih.gov/pmc/articles/PMC3911811/

11. Sanocka-Maciejewska D, Ciupinska M, Kurpisz M. Bacterial infection and semen quality. J Reprod Immunol 2005;67:51-6. [CrossRef]

12. Comhaire FH, Christophe AB, Zalata AA, Dhooge WS, Mahmoud AM, Depuydt CE. The effects of combined conventional treatment, oral antioxidants and essential fatty acids on sperm biology in subfertile men. Prostaglandins Leukot Essent Fatty Acids 2000;63:159-65. [CrossRef]

13. Zalata A, Hafez T, Comhaire F. Evaluation of the role of reactive oxygen species in male infertility. Hum Reprod 1995;10:1444-51. [CrossRef]

14. Fraga CG, Motchnik PA, Shigenaga MK, Helbock HJ, Jacob RA, Ames BN. Ascorbic acid protects against endogenous oxidative DNA damage in human sperm. Proc Natl Acad Sci U S A 1991;88:11003-6. [CrossRef] 
15. Arafa M, Agarwal A, Majzoub A, Panner Selvam MK, Baskaran S, Henkel R, Elbardisi H. Efficacy of Antioxidant Supplementation on Conventional and Advanced Sperm Function Tests in Patients with Idiopathic Male Infertility. Antioxidants (Basel) 2020;9:219. [CrossRef]

16. Bassiri F, Tavalaee M, Dattilio M, Nasr-Esfahani MH. Micronutrients in Support to The Carbon Cycle Activate Antioxidant Defences and Reduce Sperm DNA Damage in Infertile Men Attending Assisted Reproductive Technology Programs: Clinical Trial Study. Int J Fertil Steril 2020;14:57-62. [CrossRef]

17. Pena ST Jr, Gummow B, Parker AJ, Paris D. Antioxidant supplementation mitigates DNA damage in boar (Sus scrofa domesticus) spermatozoa induced by tropical summer. PLoS One 2019;14:e0216143. [CrossRef]

18. Showell MG, Mackenzie-Proctor R, Brown J, Yazdani A, Stankiewicz MT, Hart RJ. Antioxidants for male subfertility. Cochrane Database Syst Rev 2014:CD007411. [CrossRef]
19. Majzoub A, Agarwal A. Systematic review of antioxidant types and doses in male infertility: Benefits on semen parameters, advanced sperm function, assisted reproduction and live-birth rate. Arab J Urol 2018;16:113-24. [CrossRef]

20. Ahmadi S, Bashiri R, Ghadiri-Anari A, Nadjarzadeh A. Antioxidant supplements and semen parameters: An evidence based review. Int J Reprod Biomed (Yazd) 2016;14:729-36. [CrossRef]

21. Dutta S, Majzoub A, Agarwal A. Oxidative stress and sperm function: A systematic review on evaluation and management. Arab J Urol 2019;17:87-97. [CrossRef]

22. Sigman M, Glass S, Campagnone J, Pryor JL. Carnitine for the treatment of idiopathic asthenospermia: a randomized, double-blind, placebo-controlled trial. Fertil Steril 2006;85:1409-14. [CrossRef]

23. Rolf C, Cooper TG, Yeung CH, Nieschlag E. Antioxidant treatment of patients with asthenozoospermia or moderate oligoasthenozoospermia with high-dose vitamin $\mathrm{C}$ and vitamin E: a randomized, placebo-controlled, double-blind study. Hum Reprod 1999;14:1028-33. [CrossRef] 